Edith Cowan University

Research Online

Research outputs 2011

2011

Career choice perceptions of undergraduate event, sport and recreation management students: An Australian case study

Ruth D. Sibson

Edith Cowan University

Follow this and additional works at: https://ro.ecu.edu.au/ecuworks2011

Part of the Education Commons

10.3794/johlste.102.371

Sibson, R. D. (2011). Career choice perceptions of undergraduate event, sport and recreation management students: An Australian case study. Journal of Hospitality, Leisure, Sports and Tourism Education, 10(2), 50-60. Available here

This Journal Article is posted at Research Online.

https://ro.ecu.edu.au/ecuworks2011/213 
Title:

Career choice perceptions of undergraduate Event, Sport and Recreation Management students: An Australian case study

\section{Author:}

Dr Ruth Sibson

School of Marketing, Tourism and Leisure

Faculty of Business and Law

Edith Cowan University

270 Joondalup Dr, Joondalup

Western Australia 6027

Australia

Tel: (61 8) 63045600

Fax: (61 8) 63045840

\section{r.sibson@ecu.edu.au}

Bio:

Ruth Sibson, $\mathrm{PhD}$, is a Senior Lecturer at Edith Cowan University in Perth Western Australia. She coordinates the Sport, Recreation \& Event Management programs and more recently has been appointed as the Director of Undergraduate Studies for the Faculty of Business \& Law. Her research interests focus upon community sport and recreation opportunities for all citizens and business education. She is also currently the Secretary for the Australia and New Zealand Association for Leisure Studies (ANZALS). 


\title{
Career choice perceptions of undergraduate Event, Sport and Recreation Management students: An Australian case study
}

\begin{abstract}
Career choice in traditional disciplines has been well documented. The tourism and hospitality industries have also gained some attention, however, career choice research in the event, sport and recreation does not seem to have been addressed to any great extent. Knowing what students are looking for in a career is central to their attraction and recruitment into university degrees and, thus, these industries. The purpose of this exploratory study was to examine the factors undergraduate university students $(n=62)$ studying event, sport and recreation management find important when looking for a career. The results indicated that having enjoyable work in the areas they were interested in (most notably, sport and events), and having good and a variety of career opportunities, and pleasant working conditions were the most significant. Working with, and helping and influencing others, and having opportunities for creativity and originality were also important. In contrast, factors such as professional prestige/high status, hours of work and salary did not rate as highly.
\end{abstract}

\section{Key words}

Undergraduate university students; career choice; event, sport and recreation management 


\section{INTRODUCTION}

Career choice is a complex and multifaceted phenomenon, which makes it difficult to predict and understand. There are a number of competing theoretical approaches for occupational selection or career choice, however, it is best understood as the interplay between individual agency and the contextual factors of structure and culture which enhance or construct one's social world (Ozbilgin, Kusku, \& Erdogmus, 2005). There have been a number of studies across a range of the more traditional disciplines examining why students choose to be a nurse, a teacher or a dentist (e.g. Chuene, Lubben, \& Newson, 1999; Dockery \& Barns, 2005; Gallagher, Clarke and Wilson, 2008; Kyriacou \& Coulthard, 2000; Kyriacou, Coulthard, Hultgren \& Stephens, 2002; Yong, 1995; Young 1995). There have also been studies examining business degrees and majors within those degrees, and how the choice of these might link to future employment opportunities. Again, these have examined the more traditional business disciplines such as accounting, finance, economics, marketing and management (e.g. Argarwala, 2008; Auyeung \& Sands, 1997; Kim, Markham, \& Cangelosi, 2002; Ozbilgin et al., 2005; Swenson, Swinyard, Langrehr, \& Smith, 1993; Tanova, Karataş-Özkan, \& İnal, 2008).

The discipline of management and the offerings by many of the new generation of universities in Australia and worldwide are increasingly encompassing the specialisations of tourism, hospitality (or hotel), sport, event and, in some cases, recreation management. These courses are increasingly popular amongst students as they seek to study applied business principles and practices to their industry or sector of interest (Airey \& Tribe, 2005; Shilbury \& Kellett, 2010). In general, these sectors or industries are also less well-defined than say nursing or teaching, so in many ways it is even more important to know what factors are significant to individuals who seek career opportunities within them. Research focusing on tourism and hospitality as a career choice in undergraduate students has gained some attention (e.g. Akiş Roney \& Öztin, 2007; Barron, Maxwell, Broadbridge, \& Ogden, 2007; Kuşluvan \& Kuşluvan, 2000; Richardson, 2009), however, the career choice of students studying in the areas 
of event, sport and recreation management does not seem to have been addressed to any great extent by researchers.

The purpose of this paper, therefore, is to identify the factors students studying event, sport and recreation management find important when looking for a career. From an educator's perspective, knowing what factors drive or influence these students in their future career is important for their attraction and retention. For example, it enables institutions to focus on teaching and promoting the aspects students identify as important in a career in these industries (such as the ability to improve social outcomes by working closely with the community in sport or recreation programs). More importantly, the industries as a whole could also benefit from a clearer understanding of what students perceive as important in a career and could use this information in their own recruitment of the best graduates and retention of high quality staff. For example, using the knowledge that graduates are seeking a range and variety of opportunities in their career, or that they are seeking a career which allows them to be creative and original, or to work with and help others, can empower organisations to consider, integrate and promote these aspects when creating position descriptions and career pathways through internal promotions opportunities.

\section{Research on career choice of students: Theoretical approaches in}

\section{traditional disciplines}

As noted above, different theoretical approaches have been used in the study of occupational selection or career choice. Some of these emphasise the power of an individual's characteristics or agency, focusing on aspects such as personality, disposition, interest and attitude, with the overarching argument that these characteristics are dominant in shaping an individual's career. The other opposing view is that structural and organisational considerations and constraints, and cultural norms, make available and/or limit career choice opportunities (Ozbilgin et al., 2005). Theories which privilege either one of these 
notions of the individual or social structures have been criticised by a number of academics (Albert \& Luzzo, 1999; Fitzgerald \& Betz, 1994; Mignot, 2000; Ozbilgin et al., 2005). Rather, they argue there needs to be a greater appreciation of the interplay between a variety of influences, with the recognition that individuals both actively construct and are enhanced and constrained by the world in which they live (Albert \& Luzzo, 1999; Mignot, 2000; Ohman, Stenlund, \& Dahlgren, 2001; Ozbilgin et al., 2005; Woolnough et al., 1997).

Previous studies have used various classifications or scales to identify the factors that influence students' career choice, and often these factors are grouped into the broad categories of extrinsic, interpersonal, and intrinsic/altruistic (e.g. Auyeung \& Sands, 1997; Beynon, Toohey \& Kishor, 1998; Dockery \& Barns, 2005; Paolillo \& Estes, 1982). For example, Dockery and Barns (2005) used a 20 factor scale which included a range of job attributes and individual motives, in their study of what first year nursing students were looking for in an occupation. Those who chose to study nursing placed less priority on long term financial rewards and professional prestige/high status, and more emphasis on caring and working with people, and having a career which enabled them to balance their future family commitments and expectations. The attraction to nursing as a career choice appears to depend on the intrinsic characteristics of the individual, where 'interesting work' ranked highest of all factors, as well as good career opportunities, flexibility and security (Dockery \& Barns, 2005).

Similarly, Kyriacou and Coulthard (2000) and Kyriacou et al. (2002) investigated undergraduate students' views of teaching as a career choice by asking them to rate the importance of 20 nominated factors. According to these authors, many of the studies that have examined the motivations of those who decide to become teachers (e.g. Chuene et al., 1999; Yong, 1995; Young 1995) have identified factors which can largely be categorised into the three areas of: 
1. altruistic reasons: those with service themes, such as seeing the career as socially worthwhile and important, helping and influencing others and improving society;

2. intrinsic reasons: those which reflect themes of personal satisfaction and having an interest in the subject and career itself; and

3. extrinsic reasons: those with social mobility themes, covering aspects such as the job market, security, money and incentives.

In these studies, the influence of others was categorised as an extrinsic reason (see Yong, 1995). Moreover, as Yong (1995) points out, much of the literature suggests that individuals pursue teaching as a career largely for altruistic and/or intrinsic reasons. Individuals who choose teaching tend to rely on factors such as their perceived teaching ability, positive prior experiences, having time for family, job security and transferability and social utility values. Social utility values, or altruistic reasons, include "the desire to shape the future, enhance social equity, make a social contribution and work with children/adolescents" (Richardson \& Watt, 2006, p. 51).

Research has also been conducted on why students choose different physical and medical science careers. Gallagher, Clarke and Wilson (2008) discuss that individuals chose dentistry because it offered prestige and status, financial benefits, it linked in with their personal interest, it offered job security, flexibility and independence, as well as a rich quality of life, and others had encouraged them to pursue it. Interestingly, although mentioned, the desire to help people was not a dominant factor. Woolnough et al.'s (1997) research into factors affecting student choice of a career in science and engineering highlighted the most influential factors as the perceived attractiveness of a career in science itself, the likelihood of job satisfaction, the perceived status and salary. They also add, however, that the quality of science lecturers, intellectual satisfaction and early involvement in extracurricular activities such as science competitions and hobbies, were considered important, and noted that the importance of all of these factors varied across students in different countries. In fact, the influence of various factors on the career choice in students have been shown to vary 
significantly across cultures, due largely to differences in attitudes and notions of collectivism (found mainly in countries in Asia, South America and Africa) versus individualism (found mainly in Western cultures such as North America, northern and western Europe and Australia) (Auyeung \& Sands, 1997; Hofstede, 1980, Ozbilgin et al., 2005).

Thus, as the studies discussed here have shown, although there may be a range of recurring factors that influence a student's choice of career, they do vary in importance according to the career, and they do vary according to cultural values, norms and beliefs. It is also important to recognise that decisions regarding occupations or careers change over time. In reality, there will be a number of influences, interactions, turning points and transformations which affect an individual's choice of career or career path throughout their lifetime (Ohman et al., 2001; Tanova et al., 2008).

As evidenced above, many of the studies on career choice have been conducted on traditional occupations such as teaching, engineering, nursing, dentistry and other health-related professions. In the broad area of business, much of the focus of career choice has also been on the traditional undergraduate majors such as accounting, marketing and information systems (e.g. Auyeung \& Sands, 1997; Kim et al., 2002; Swenson et al., 1993) or on students studying an MBA (e.g. Argarwala, 2008; Ozbilgin et al., 2005; Tanova et al., 2008). In their study of why US students studying a range of majors (e.g. accounting, finance, management, marketing, and information systems) pursue business degrees, Kim et al. (2002) found the primary reasons to be interest in the type of work associated with their major, good job opportunities (including self-employment), a good match with their capabilities and future earnings. Conversely, other factors such as reputation of the institution, perceived quality of the teaching, and influences such as course promotion, parents and friends had a negligible impact. There was some difference amongst students studying different majors. For example, job opportunities ranked higher, than interest in the work for students studying information systems, and finance students ranked projected earnings higher than students studying other majors. 
However, the overall ranked order of a range of reasons was generally consistent across the majors.

Research on career choice in the 'new' generation of business students: Tourism, Hospitality, Sport, Event and Recreation Management

Research focusing on tourism and hospitality as a career choice has gained some attention and, in many ways, Ross (1991; 1992a, 1992b; 1994) is considered the pioneer in this area. His early research focused on Australian secondary high school students' employment attitudes and preferences regarding the tourism and hospitality industries. He found that these students did have a high level of interest, particularly in management positions, within the industries. Moreover, it was suggested that the students who did show an interest in this managerial work, had a higher level of commitment to notions of achievement, productivity and maximising professional goals (Ross, 1992a). Similarly, the early work by Getz (1994) focused on high school students in Scotland, UK, and their attitudes towards careers in hospitality and tourism, while Airey and Frontis (1997) conducted a comparison on secondary school pupils' attitudes to careers in tourism in Athens, Greece and Nottingham, UK. Their work, like that of Ross (1991; 1992a, 1992b; 1994), highlighted the need for the creation of more accurate information and awareness of these industries, as well as the specific careers within them, along with more support for education and training. Ross (1992a) recommended that universities in countries such as Australia should engage more purposively in management education relevant to the tourism and hospitality industries, rather than simply relying on 'in-house industry training', and that this education must directly serve the needs of industry as well as its present and future employees.

Significantly, in Australia and in many other countries, this appears to have happened. The availability of majors or degrees in business has been extended to the specific industries or sectors of tourism, and hospitality or hotels, as well as sport, events and in some cases recreation. However, Richardson (2009) still 
argues that apart from a few studies there has been little consideration given to career choice of undergraduate students in tourism and hospitality management courses. By and large, the majority of these early studies have focused on secondary high school students' perceptions towards tourism and/or hospitality as a job or career path (e.g. Airey \& Frontistis, 1997; Getz, 1994; Ross, 1991; 1992a, 1992b; 1994), and more recently of workers' (Choy, 1995) and undergraduate students (e.g. Akiş Roney \& Öztin, 2007; Barron et al., 2007; Kuşluvan \& Kuşluvan, 2000; Richardson, 2009) perceptions and attitudes towards employment and careers within the tourism and hospitality industries.

Richardson's (2009) most recent study, however, explored the perceptions of Australian students studying tourism and hospitality management of both the importance of a set of factors related to their choice of career and the extent to which a career in these industries would offer those factors. In terms of the importance of career choice factors he found that having an enjoyable job, pleasant working environment, job security, colleagues they can get along with and high earnings over the length of their career were the most important. Conversely, having a job which could be combined with parenthood, where they could care for others and contribute to society, and have the opportunity to travel abroad were of least importance.

The career choice of students studying in the areas of event, sport and recreation management does not seem to have been addressed to any great extent by researchers. The research which has examined the factors that influence career choice from a range of disciplines, as outlined above in this literature review, certainly has relevance and application to this area. The purpose of this study, therefore, is to examine the factors students studying event, sport and recreation management find important when looking for a career. Understanding the views of these students is central to the attraction and recruitment of students into such courses, which are increasing in popularity, particularly in the domain of event management. It also allows career misconceptions to be identified, enabling program staff to portray courses more realistically and to some extent prevent future job dissatisfaction. Marketing 
campaigns and course design can also cater towards attracting quality students to meet the needs of the relevant industries (Kim et al., 2002). It is also essential for the employers in these industries to know what the potential graduates see as important and want from a career. To attract and retain the best employees, employers need to know what they are looking for in a career, and then focus or tailor their job advertisements and future career pathways to meet these demands.

\section{METHODS}

Similar to previous studies which have sought to indentify the factors students consider important in a future career, this study employed a quantitative approach through the use of a self-completed, anonymous questionnaire survey. A quantitative approach and questionnaires were considered the most appropriate method for data collection as it allowed for the systematic collection of quantifiable data on a set of pre-determined variables, as well as some openended responses, in a quick and efficient manner. At the same time, it enabled the maximisation of responses. The questionnaire was distributed to all Bachelor of Event, Sport and Recreation Management (BESRM) students who were enrolled in, and subsequently attended the first seminar of, one of the course's introductory units in the years of 2008 and 2009 at Edith Cowan University in Perth, Western Australia. The research received approval from, and followed the ethical guidelines, of the university's Human Research Ethics Committee. An information letter was provided to students to ensure they had full knowledge of their rights and the purpose of the research; participation was entirely voluntary with no coercion or pressure of any kind placed upon them to participate.

First, basic demographic information was asked of participants and then an open-ended question allowed students to outline up to three separate things that were important to them in looking for a future career. As the next question in the survey, students rated the importance of 21 factors in looking for a career 
on a five-point Likert scale measure. Values assigned to the responses were: 1 = very unimportant; 2 = unimportant; 3 = neither important or unimportant; $4=$ important; and 5 = very important. The factors were based on two previously published studies from the disciplines of nursing and teaching respectively (Dockery \& Barns, 2005; Kyriacou \& Coulthard, 2005), as well as considerations specific to the event, sport and recreation industries. For example, the factors of 'range/variety of career opportunities', and 'transferability of work skills' were specifically added to the questionnaire as elements important to these industries, but not necessarily relevant those seeking to be a nurse or a teacher. Although the questionnaire was anonymous, students were asked to sign a class attendance role once they completed the survey so that the response rate could be ascertained. The quantitative data were analysed using the Statistical Package for the Social Sciences (SPSS). The open-ended responses were analysed through broad content analysis and the identification of key themes.

\section{RESULTS}

A total of 62 students, who were enrolled in the BESRM course and were enrolled in, and attended, the first seminar of the introductory core unit in 2008 and 2009, completed the questionnaire. This total represents a response rate of $91 \%$. The nature of the student sample is shown in Table 1.

\section{INSERT TABLE 1 HERE}

The sample comprised 40 female students and 22 male students, who were aged between 17 and 37 years (with the average age being 19). The majority were domestic students (95.2\%), which includes Australian citizens and permanent residents, with two from China and one from the Netherlands. As expected, given the introductory unit to which students were enrolled, most students were in their first semester of study (87.1\%), with the majority also studying full-time (91.9\%). Students were also asked the approximate number of hours they would work while studying; answers ranged between zero and 40 
hours, with the average being 16.6 hours per week. There were only five students (8.1\%) who indicated they would not work at all while studying.

\section{Importance of factors in looking for a career}

Students were asked to rate the importance of a number of specified factors when looking for a career. Table 2 shows the number of respondents, mean scores and standard deviations for each of the 21 choice factors. The factors are ranked from the highest mean score of importance for the factor 'enjoyable work' (4.70) to the lowest mean score for the factor 'standard hours of work i.e. 9 to $5^{\prime}$ (3.49). In an open-ended question, students were also asked to outline three separate things that were important to them in looking for a future career. The quantitative results allow for statistical ranking of the relative importance of the nominated factors to students through their mean score, while the qualitative responses are used to illustrate students' thoughts on their career choice.

\section{INSERT TABLE 2 HERE}

The two factors with the highest mean score were 'enjoyable work' (4.70) and 'interesting work' (4.66) indicating that individual interest in the choice of a career is of paramount importance. To round out the top six factors according to mean score, three related to career and employment opportunities: 'good career opportunities' (4.54); 'availability of jobs' (4.49) and 'range/variety of career opportunities' (4.43), and one focused on the setting in which the work was to take place through 'pleasant working conditions' (4.44). The rating of these factors indicates that the variety of opportunities and employment prospects a career can provide, alongside the workplace environment, are very important. These results correspond to the key reasons students noted in the open-ended questions, in that having interest in the work they were going to do and for many, having a passion or a love for their career was important: "Interest is very important for me getting a job"; "Getting paid to do something I love"; and "Something I am passionate about". Strongly related to this notion of interest were perceptions of enjoyment: "Enjoyment - I'm not focused too much on 
money if I can make a decent living, I would like to do something I enjoy". For some students the need to enjoy their work was balanced against their need not to hate it: "Something I really enjoy doing, not waking up to dread going to work". As well as focusing on the availability of job opportunities: "Ease of finding a job - availability or demand" and the variety of work opportunities: "Versatility - I would like to be able to do a range of different things in the industry", students also specifically indicated that within their chosen job, they sought variety in their daily activities: "Something diverse, not doing the same thing everyday".

The factors relating to job conditions were quite mixed. As noted above, having pleasant working conditions was ranked quite highly. 'Job security' also ranked in the top-third of the 21 factors with a mean score of 4.28 . Having 'opportunities for promotion/advancement' within their career was ranked slightly below with a mean score of 4.21. However, the hours of work, in either having standard or flexible approach were not so important, with 'standard hours of work (i.e. 9 to 5)' (3.49) being ranked least important of all 21 factors and 'flexible hours of work' (3.98) ranked $18^{\text {th }}$.

In the open-ended responses students did indicate that having the opportunity for individual growth and promotion within a career was important and spoke of aspects such as: "Being able to progress through the ranks of the career I choose"; or "Space for me to move up and advance my career"; and "Promotion and new experiences - that every job or opportunity can help extend or encourage new skills and learning". However, other aspects relating to aforementioned job conditions were not referred to.

The factor of a 'good graduate/starting salary' (4.03) was not seen as important as 'good future earnings potential' (4.25), however, both of these were more important than 'professional prestige/high status of future career' (3.85) which was ranked as the second least important factor. When comparing across the factors, though, 'good graduate/starting salary' and 'professional prestige/high status of future career' did have some of the highest standard deviation scores at 0.856 and 0.853 respectively indicating the higher levels of variability 
amongst students for these requirements. Salary and income were mentioned by some students in their open-ended responses. For those who provided an explanation, it related to their income being satisfactory to support their living expenses or needs: "The pay must be reasonable to support living needs in the future"; "A good income which will allow me to support myself and live a good life"; and "Earn enough money to live comfortably". Only one student stated that having an "excellent income" was important. The aspects of status were less prominent, but were still mentioned by some who explained that "Being well known and recognisable"; and "Status emerging from the career chosen" were important.

The ability to work with and influence people, as well as make a contribution to society were seen as reasonably important with the factors of 'ability to make a contribution to society' (4.23), 'opportunities to work closely with people' (4.08) and 'opportunities to influence other people' (4.08) ranking as $10^{\text {th }}$ and equal $12^{\text {th }}$ respectively. These responses were noticeable in the open-ended responses where, working with, and meeting, other people were cited as important. Students spoke of wanting: "The opportunity to work with others in the same interest"; and "The opportunity to meet heaps of people"; and "Where I can mix with a variety of people from all different walks of life", with some students indicating they wish to help others through their work: "Something which helps others and makes them happy"; and "To help people learn, enjoy life and be a valued member of society"

Of interest in the quantitative findings was that students indicated that having 'challenging work' (3.97) was of less importance than many of the nominated factors, but having 'responsibility involved in job' (4.08) was of more importance ranked 14 of the 21 factors. More important than both of these though, were 'opportunities for creativity and originality', with a mean score of 4.28 ranking the factor equal $7^{\text {th }}$. The factors of 'opportunities for travel' and 'transferability of work skills' both had mean scores of 4.02 and were ranked in the bottom-third of factors. The factor 'opportunities for travel' did record the highest standard 
deviation of any factor at 1.041 indicating the high variability of the importance of being able to travel as part of their career across the student cohort.

Having the opportunity to travel as part of their future work was noted by some students in their qualitative responses: "Opportunities to travel around the world with my job/career"; and "A move to the Eastern states would also be a desire to get experience before heading to Europe". However, the notions of challenging work, responsibility, transferability of skills and creativity/originality were not touched upon.

One key theme which did come through the qualitative responses, which was not evident in the list of factors, related to the students' ability and knowledge to follow their desired career path. This related to perceptions of self and included having the appropriate skills, experience and qualifications to enter and work in these industries: "Being a capable and knowledgeable professional"; "Experience - because in this industry it's a very important factor"; and "That I have the right qualification for my career". Not surprisingly, given the course they had enrolled in, students also specifically mentioned that they wanted to work in the sport and event industries: "I want to work with sports"; "Working in the sport industry"; and "Work in the event and sport management industry". However, there was no mention of the recreation sector; though one student spoke of wanting to be involved in "Arts/sports/event management".

\section{DISCUSSION}

There were numerous factors that students, who were largely in their first semester of the Bachelor of Event, Sport and Recreation Management course, saw as important to them in a career. However, the intrinsic reasons of having enjoyable work in the areas they were interested in (most notably, sport and events), and the more extrinsic reasons of having good and a variety of career opportunities, and pleasant working conditions were the most significant. Not surprisingly, these results are similar to a number of other studies from a range of disciplines (e.g. Dockery \& Barns, 2005; Kyriacou \& Coulthard, 2000; Richardson, 2009) indicating that there may be some intrinsic and extrinsic 
dimensions of career choice which are central to any individual who seeks to be acknowledged as a competent, relevant, and credible member of a Western labour force and, therefore, effective citizen of society (Rojek, 2010). It is the identification and analysis of many of the other key factors and their differentiation from students of other discipline areas, however, which provide an insight into this particular student cohort and offers academics and industry professionals potentially useful information for the future recruitment and retention of students or employees. In this study, these key factors related largely to aspects of social mobility and working with, and serving, the community.

Significantly, although a good starting salary and future earnings potential was still important to students in this course they were not one of the top priorities, and the qualitative results of this study indicated that earnings potential was more likely to be related to a notion of off-setting living expenses and having enough money to be comfortable, rather than pure financial gain. In many ways, this is in contrast to previous studies which have focused on traditional business disciplines and/or the tourism and hospitality industries. In Richardson's (2009) study of undergraduates studying tourism or hospitality management, for example, 'high earnings over the length of career' was the fifth most important factor (of a list of 20 factors), and in Kim et al.'s (2002) study of students studying business majors 'projected earnings in the related career' also ranked as the fifth most important reason (from a list of 10). In examining another social mobility theme, it is evident that professional status/prestige was not really considered as important as a range of other factors to students in this degree. This result is similar to those studying nursing (Dockery \& Barns, 2005), but in contrast to other non-business disciplines such as dentistry, science and engineering (Gallagher et al., 2008; Woolnough et al., 1997).

On the other hand, it seems that wanting to contribute to society is more important to these students, than to those studying tourism or hospitality management. In Richardson's (2009) study, two of the lowest ranked factors $\left(18^{\text {th }}\right.$ and $19^{\text {th }}$ out of 20 ) were 'a job where I will contribute to society' and 'a job 
where I can care for others'. This is clearly not the case with this student cohort, where thoughts of helping others and social interaction were noted as important in both the qualitative and quantitative results. The 'ability to make a contribution to society', for example, was ranked as $10^{\text {th }}$ with a mean of 4.23 , and 'opportunities to influence other people' and 'opportunities to work closely with people' were ranked equal $12^{\text {th }}$ with a mean of 4.08 . These results suggest that altruistic reasons, such as helping and influencing others and improving society are important to students studying event, sport and recreation management, and in many ways these students share similarities with those studying nursing and/or teaching (Dockery \& Barns, 2005; Kyriacou \& Coulthard, 2000; Kyriacou et al., 2002).

One of the other more surprising results, which should be of interest to educators and employers, is the ranking of 'opportunities for creativity and originality' as equal $7^{\text {th }}$ with a mean of 4.28 . This factor was ranked higher than all of the aforementioned themes of income, prestige/status and working with and helping others. Working with the community and providing sport, recreation and event activities and programs for cultural, social and health benefits certainly provides opportunities for creativity and originality, and clearly appeals to the current generation of students seeking a career in these industries. It is recommended, therefore, that this aspect be more clearly identified and focused on as a desirable feature of a career in these industries.

\section{CONCLUSIONS}

We must remember that each individual has different influences and that they differ at varying points in their life, and that this study has been conducted at one point in these students' lives. However, from the findings of this and other similar studies, it can be argued that, generically, career choice is about having enjoyable and interesting work and a pleasant work environment which offers a range of job and career opportunities. There are a range of other factors, however, that must attract people to work in certain industries. 
The results of this study, which focused on students recently enrolled in the event, sport and recreation management Bachelor degree, indicate that there are some areas educators and employers could target in their recruitment and retention strategies. First, it would make sense to target those showing an interest in these industries - whether it be through formal school or vocational education (e.g. physical and outdoor education subjects or sport and recreation traineeships), or informally through community or State sport and recreation organisations and/or events. Second, both the tertiary sector and the industry could do more to provide information on the type, range and variety of careers available and within this focus on the working conditions as a positive aspect. Third, there is a real opportunity to extend this focus on the careers within these industries to highlight further the opportunities there are to work with, and assist, people in their day to day work. Moreover, focusing on the opportunities people have for originality and creativity in their various roles may further attract those with this interest into the workforce. From the results of this study, these are key points of differentiation between event, sport and recreation management and many other business disciplines, and it would be well worth managers using this information to their advantage. There is also considerable room for future research in this area.

This study focused on students who were newly enrolled into one specific event, sport and recreation management degree, but students who are at different stages of their course are likely to have differing views on career choice, and the views of those in their final year would be of particular interest to employers of new graduates. Further research on career choice of students in similar courses, perhaps in a longitudinal study, with more diverse, and larger, student cohorts is also required, as well as investigating differences in demographic variables such as gender, age, and domestic versus international students. It would also be worthwhile exploring a number of the factors of interest identified in this paper in a qualitative study to gain a better understanding of why some factors are more important than others. Researchers may also want to explore career choice more fully with those already working in the industry as good human resource management and, in 
particular, retention of high quality employees requires recognition of the different levels and stages of career development.

\section{REFERENCES}

Airey, D., \& Frontis, A. (1997). Attitudes to careers in tourism: An Anglo Greek comparison. Tourism Management, 18(3), 149-158.

Airey, D., \& Tribe, J. (2005). (Eds.). An international handbook of tourism education. Oxford, UK; Elsevier

Albert, K. A., \& Luzzo, D. A. (1999). The role of perceived barriers in career development: A social cognitive perspective. Journal of Counseling \& Development, 77(4), 431-437.

Fitzgerald, L. F. \& Betz, N. E. (1994). Career development in a cultural context: The role of gender, race, class, and sexual orientation. In M. L. Savickas \& R. W. Lent (Eds.), Convergence in career development theories: Implications for Science and Practice, pp. 103-117. Palo Alto, CA: Consulting Psychologists Press.

Akiş Roney, S., \& Öztin, P. (2007). Career perceptions of undergraduate tourism students: A case study in Turkey. Journal of Hospitality, Leisure, Sport \& Tourism Education, 6(1), 4-17.

Argarwala, T. (2008). Factors influencing career choice of management students in India. Career Development International, 13(4), 362-376.

Auyeung, P., \& Sands, J. (1997). Factors influencing accounting students' career choice: A cross-cultural validation study. Accounting Education, 6(1), 13-23.

Barron, P., Maxwell, G., Broadbridge, A. \& Ogden, S. (2007). Careers in hospitality management; Generation Y's experiences and perceptions. Journal of Hospitality and Tourism Management, 14(2), 119-128. 
Beynon, J., Toohey, K., \& Kishor, N. (1998). Do visible minority students of Chinese and South Asian ancestry want teaching as a career?: Perceptions of some secondary school students in Vancouver, BC. Canadian Ethnic Studies, 30(2), 50-73.

Choy, D. J. L. (1995). The quality of tourism employment. Tourism Management, 16(2), 129-137.

Chuene, K., Lubben, F., \& Newson, G. (1999). The views of pre-service and novice teachers on mathematics teaching in South Africa related to their educational experience, Educational Research, 41(1), 23-34.

Dockery, A., \& Barns, A. (2005). Who'd be a nurse? Some evidence on career choice in Australia. Australian Bulletin of Labour, 31(4), 350-383.

Gallagher, W., Clarke, W., \& Wilson, N. (2008).Understanding the motivation: A qualitative study of dental students' choice of professional career. European Journal of Dental Education, 12(2), 89-98.

Getz, D. (1994). Students' work experiences, perceptions and attitudes towards careers in hospitality and tourism: A longitudinal case study in Spey Valley, Scotland. International Journal of Hospitality Management, 13(1), 25-37.

Hofstede, G. (1980). Culture's consequences: International differences in workrelated values. Beverly Hills, CA: Sage.

Kim, D., Markham, F., \& Cangelosi, J. (2002). Why students pursue the business degree: A comparison of business majors across universities. Journal of Education for Business, 78(1), 28-32.

Kyriacou, C., \& Coulthard, M. (2000). Undergraduates' views of teaching as a career choice. Journal of Education for Teaching, 26(2), 117-126.

Kyriacou, C., Coulthard, M., Hultgren, A., \& Stephens, P. (2002). Norwegian university students' views on a career in teaching. Journal of Vocational Education and Training, 54(1), 103-116. 
Kuşluvan, S. \& Kuşluvan, Z. (2000). Perceptions and attitudes of undergraduate tourism students towards working in the tourism industry in Turkey. Tourism Management, 21, 251-269.

Mignot, P. (2000). Metaphor: A paradigm for practice-based research into 'career'. British Journal of Guidance \& Counselling, 28(4), 515-531.

Ohman, A., Stenlund, H., \& Dahlgren, L. (2001). Career choice, professional preferences and gender: The case of Swedish physiotherapy students, Advances in Physiotherapy, 3, 94-107.

Ozbilgin, M., Kusku, F., \& Erdogmus, N. (2005). Explaining influences on career 'choice': The case of MBA students in comparative perspective. Journal of Human Resource Management, 16(11), 2000-2028.

Paolillo, J. G. P. \& Estes, R. W. (1982). An empirical analysis of career choice factors among accountants, attorneys, engineers, and physicians. The Accounting Review, 57(4), 785-793.

Richardson, P., \& Watt, H. (2006). Who chooses teaching and why? Profiling characteristics and motivations across three Australian universities. AsiaPacific Journal of Teacher Education, 34(1), 27-56.

Richardson, S. (2009). Undergraduates' perceptions of tourism and hospitality as a career choice. International Journal of Hospitality Management, 28 382-388.

Rojek, C. (2010). The labour of leisure: The culture of free time. London: Sage.

Ross, G. F. (1991). School leavers and their perceptions of employment in the tourism/hospitality industry. The Journal of Tourism Studies, 2(2), 28-35.

Ross, G. F. (1992a). Tourism management as a career path: Vocational perceptions of Australian school leavers. Tourism Management, 13(June), 242-247. 
Ross, G. F. (1992b). Tourism and hospitality industry job-attainment beliefs and work values among Australian school leavers. International Journal of Hospitality Management, 11(4), 319-330.

Ross, G. F. (1994). What do Australian school leavers want of the industry? Tourism Management, 15(1), 62-66.

Shilbury, D. \& Kellett, P. (2010). Sport management in Australia: An organisational overview (4 ${ }^{\text {th }}$ ed.). Sydney, NSW: Allen \& Unwin.

Swenson, M. J., Swinyard, W. R., Langrehr, F. W., \& Smith, S. M. (1993). The appeal of personal selling as a career: A decade later. Journal of Personal Selling and Sales Management, 13(Winter), 51-64.

Tanova, C., Karataş-Özkan, M., \& İnal, G. (2008). The process of choosing a management career: Evaluation of gender and contextual dynamics in a comparative study of six countries - Hungary, Israel, North Cyprus, Turkey, UK and the USA. Career Development International, 13(4), 291305.

Woolnough, B., Guo, Y., Leite, M., De Almeida, M., Ryu, T., Wang, Z., \& Young, D. (1997). Factors affecting student choice of career in science and engineering: Parallel studies in Australia, Canada, China, England, Japan and Portugal. Research in Science and Technological Education, 15(1), 105-121.

Yong, B. C. S. (1995). Teacher trainees' motivation for entering into a teaching career in Brunei Darussalam. Teaching \& Teacher Education, 11(3), 275280.

Young, B. J. (1995). Career plans and work perceptions of preservice teachers. Teaching \& Teacher Education, 11(3), 281-292. 
Table 1. Personal characteristics of university student sample

\begin{tabular}{|l|l|c|c|}
\hline Characteristic & $\mathrm{N}$ & Percent \\
\hline \multirow{3}{*}{ Gender } & Male & 22 & $35.5 \%$ \\
\cline { 2 - 4 } & Female & 40 & $64.5 \%$ \\
\hline \multirow{2}{*}{ Age } & $17-19$ years of age & 48 & $77.5 \%$ \\
\cline { 2 - 4 } & 20 years of age or older & 14 & $22.5 \%$ \\
\hline \hline \multirow{3}{*}{ Student } & Domestic (Australian citizen or resident) & 59 & $95.2 \%$ \\
\cline { 2 - 4 } & International & 3 & $4.8 \%$ \\
\hline \hline \multirow{3}{*}{$\begin{array}{l}\text { Study status } \\
\text { semester }\end{array}$} & Full-time (3 or 4 units per semester) & 57 & $91.9 \%$ \\
\cline { 2 - 4 } & Part-time (1 or 2 units per semester) & 5 & $8.1 \%$ \\
\cline { 2 - 4 } & $1^{\text {st }}$ semester of study & 54 & $87.1 \%$ \\
\cline { 2 - 4 } & $2^{\text {nd }}$ to 6 ${ }^{\text {th }}$ semester of study & 8 & $12.9 \%$ \\
\hline
\end{tabular}


Table 2. Importance of factors in looking for a career

\begin{tabular}{|c|c|c|}
\hline Factor & Mean & SD \\
\hline Enjoyable work & 4.70 & 0.641 \\
\hline Interesting work & 4.66 & 0.704 \\
\hline Good career opportunities & 4.54 & 0.594 \\
\hline Availability of jobs & 4.49 & 0.649 \\
\hline Pleasant working conditions & 4.44 & 0.592 \\
\hline Range/variety of career opportunities & 4.43 & 0.670 \\
\hline Job security & 4.28 & 0.662 \\
\hline Opportunities for creativity and originality & 4.28 & 0.799 \\
\hline Good future earnings potential & 4.25 & 0.745 \\
\hline Ability to make a contribution to society & 4.23 & 0.761 \\
\hline Opportunities for promotion/advancement & 4.21 & 0.798 \\
\hline Responsibility involved in job & 4.08 & 0.586 \\
\hline Opportunities to influence other people & 4.08 & 0.759 \\
\hline Opportunities to work closely with people & 4.08 & 0.822 \\
\hline Good graduate/starting salary & 4.03 & 0.856 \\
\hline Transferability of work skills & 4.02 & 0.846 \\
\hline Opportunities for travel & 4.02 & 1.041 \\
\hline Flexible hours of work & 3.98 & 0.826 \\
\hline Challenging work & 3.97 & 0.774 \\
\hline
\end{tabular}




\begin{tabular}{|l|c|c|}
\hline Professional prestige/high status of future career & 3.85 & 0.853 \\
\hline Standard hours of work (i.e. 9 to 5) & 3.49 & 0.744 \\
\hline
\end{tabular}

